\title{
Extinction and reconditioning of behavior generated by a DRL contingency of reinforcement ${ }^{1}$
}

\section{DAVID E. CARTER AND LOUIS J. J. BRUNO, DEPARTMENT OF PSYCHOLOGY, COLUMBIA UNIVERSITY, New York, N. Y. 10027}

Three groups of two rats each were given 300, 900, or 1500 water reinforcements for responses separated by at least $6 \mathrm{sec}$ (DRL $6 \mathrm{sec}$ ). When reinforcement was subsequently withheld, resistance to extinction was generally low for all Ss, although there was some indication that it increased with the number of previous reinforcements. When reinforcement was again programmed, very rapid reconditioning was found for all Ss. The data are discussed in terms of the discriminative function of the reinforcing stimulus.

Ferster \& Skinner (1957) have emphasized the possibility of differentially reinforcing a rate of response. With a DRL $6 \mathrm{sec}$ schedule, for example, it is possible to condition low rates by reinforcing successive responses only when they are separated by an interresponse time (IRT) of at least $6 \mathrm{sec}$. The present paper examines the characteristics of DRL behavior during extinction and reconditioning following 300,900 , or 1500 reinforcements.

Subjects. The Ss were six experimentally naive, male Sprague-Dawley albino rats, approximately 180 days old at the start of experimentation. For a week before the first experimental session, and also after the extinction session, the Ss were given $10 \mathrm{~min}$ access to water at the same time each day. After sessions in which water reinforcements were obtained, the Ss were limited to $5 \mathrm{~min}$ access to water in the home cage, where food was always available.

Apparatus. The experimental chamber was a Skinner box (Grason-Stadler, Model E3125A) containing a single lever. The chamber was modified so that a solenoid-operated dipper, normally in the up position, was briefly displaced downward into a reservoir and delivered $0.02 \mathrm{cc}$ of water whenever a lever press met the criterion for reinforcement. From a room adjacent to the experimental chamber, standard relay apparatus automatically programmed the reinforcement contingencies, while responses and reinforcements were recorded by counters and a curtulative recorder (Gerbrands, Model C-2).

Procedure. On the day after operant level determination and dipper approach training, bar-pressing was conditioned by reinforcing successively closer approximations to the complete response. During this session each of the first 20-30 complete bar-presses was reinforced. A 6-sec DRL contingency was then introduced and the session was continued until the rat had obtained 100 additional reinforcements. Subsequent training sessions under the same 6-sec DRL schedule were terminated after 100 reinforcements.

Since operant levels for all rats ranged from $2-4$ responses in $30 \mathrm{~min}$, Ss were assigned to groups randomly. Two rats were extinguished after 300 reinforcements, two after 900 reinforcements, and two after 1500 reinforcements. Extinction, during which bar-presses did not activate the dipper, occurred in a single 3-h session given on the day following the final DRL session. On the day after extinction, all Ss were reconditioned on the original DRL schedule until 100 reinforcements had been obtained.

Results and Discussion. The baseline response rates averaged over the two final days of DRL conditioning ranged from 6.64 to 8.86 responses per minute and were not systematically related to the number of reinforcements given during conditioning. The cumulative records taken for the same period show steady response rates for each $S$ with no indication of short IRTs, or "bursts" of responses. A typical record, obtained from a $S$ given 900 reinforcements before extinction, is shown in the upper portion of Fig. 1. The frequent occurrence of two or more reinforced responses in succession is evident here and in the records of several other experimenters, and has been shown (Farmer \& Schoenfeld, 1964) to indicate that a response meets the reinforcement contingency more often if it follows a reinforced rather than an unreinforced response. Where successive responses failed to meet the DRL contingency, reinforced responses are separated by several near-criterion responses, by long pauses, or many times by both.

The greater frequency of a reinforced response after a reinforced than after an unreinforced response is also indicated in

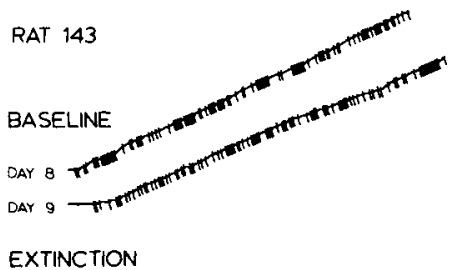

EXTINCTION

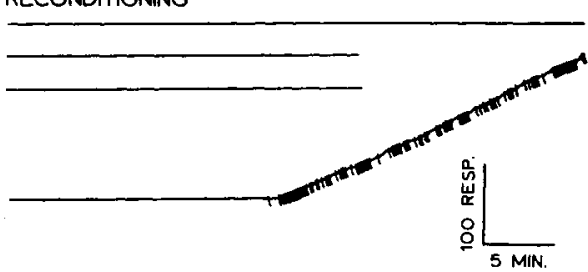

Fig. 1. Cumulative records for the last two conditioning sessions on a 6-sec DRL schedule, the extinction session, and the reconditioning session for Rat 143. The downward pips of the recorder pen mark the occurrence of reinforcements.

the ratios of reinforced to total responses shown for each rat in Table 1.2 These values are about the same for all Ss and range from 0.47 to 0.59 , except for a value of 0.78 for Rat 142 . Although comparable to the results of Ferraro, Schoenfeld, \& Snapper (1965), these values are consistently higher than those obtained by other experimenters who report extinction data (cf. Wilson \& Keller, 1953; Reynolds, 1964).

Response rates during extinction were negatively accelerated and usually reached near zero within a few minutes after the start of the session. As the cumulative record in the middle portion of Fig. 1 indicates, there was little or no tendency for any of the Ss to respond with unusually short IRTs. Long pauses generally alternated with a series of shorter IRTs.

The number of responses emitted by each $S$ during the 3-h extinction session is shown in the last column of Table 1. The range is from six responses after 300 reinforcements to 52 following 1500 reinforcements. In general, resistance to extinction increased with the number of reinforcements, but with only two Ss in each group it is difficult to make any further statement about the shape of the function.

\section{Table 1}

The Ratio of Reinforced Responses to Total Responses for the Baseline and Reconditioning Sessions for Each Rat and the Number of Responses in Extinction

\begin{tabular}{ccccc}
$\begin{array}{c}\text { Number of } \\
\text { Reinforcements }\end{array}$ & Rat & Baseline & $\begin{array}{c}\text { Ratio of Reinforced } \\
\text { to Total Responses }\end{array}$ & $\begin{array}{r}\text { Resonditioning } \\
\text { Responses in } \\
\text { Extinction }\end{array}$ \\
\hline \multirow{2}{*}{300} & 146 & 0.59 & 0.69 & 17 \\
& 147 & 0.47 & 0.75 & 6 \\
900 & 143 & 0.51 & 0.54 & 14 \\
& 144 & 0.52 & 0.66 & 51 \\
1500 & 142 & 0.78 & 0.72 & 52 \\
& 145 & 0.55 & 0.68 & 37 \\
\hline
\end{tabular}


The important point is that resistance to extinction was low after training on a DRL schedule. This finding is consistent with the data published by Ferraro et al (1965), but at variance with the data of Wilson \& Keller (1953), and of Reynolds (1964).

In the reconditioning session, all $S$ s recovered the baseline performance rapidly once the first response was emitted and reinforced, regardless of the time taken to make the first response. Four Ss emitted the first response within a few minutes after the beginning of the session, but two animals, one of which produced the record in the bottom portion of Fig. 1, did not emit the first response until nearly $2 \mathrm{~h}$ after the start of the session.

The rapid recovery of DRL performance after extinction is evident in the ratios of reinforced to total responses given in the fourth column of Table 1 . With the exception of Rat 142 whose baseline ratio was already quite high, these ratios increased for all Ss from the baseline to reconditioning sessions. Rapid reconditioning of DRL behavior has previously been reported by Ferraro et al (1965).

The finding that a response met the DRL criterion more often if it followed a reinforced rather than an unreinforced response is of particular interest. It suggests that the stimuli produced by criterion responses served not only to reinforce those responses but also to set the occasion for further reinforced responding (cf. Carter \& Bruno, 1968). That is, the reinforcing stimulus may also have served as a discriminative stimulus. Where this is the case, rapid extinction and reconditioning of DRL behavior are predicted because the two procedures are defined by the presence or absence of the discriminative stimulus.

\section{REFERENCES}

CARTER, D. E., \& BRUNO, L. J. J. On the discriminative function of the reinforcing stimulus. Psychon. Sci, 1968, 11, 21-22.

FARMER, J., \& SCHOENFELD, W. N. Effects of a DRL contingency added to a fixed-interval reinforcement schedule. J. exp. Anal. Behav., 1964, 7, 391-399.

FERRARO, D. P., SCHOENFELD, W. N., \& SNAPPER, A. G. Sequential response effects in the white rat during conditioning and extinction on a DRL schedule. J. exp. Anal. Behor., 1965, 8, 255-260.

FERSTER, C. B., \& SKINNER, B. F. Schedules of reinforcement. New York: Appleton-Century-Crofts, 1957.

REYNOLDS, G. S. Accurate and rapid reconditioning of spaced responding. J. exp. Anal. Behav., 1964, 7, 273-275.

WILSON, M. P., \& KELLER, F. S. On the selective reinforcement of spaced responses. J. comp. physiol. Psychol., 1953, 46, 190-193.

\section{NOTES}

1. This report is based on a paper presented at the 1966 meeting of the Eastern Psychological Association. Reprints are available from David E. Carter, 470 Schermerhorn Hall, Columbia University, New York, N. Y. 10027.

2. The value of the ratios in Table 1 may range from 0.0 when no responses are reinforced to 1.0 when every response is reinforced. When the value is greater than 0.5 , the frequency of reinforced responses must be greater after reinforced than after unreinforced responses. 